\title{
Safety of Bronchoscopy in Patients with Echocardiographic Evidence of Pulmonary Hypertension
}

\author{
Gilda Diaz-Fuentes ${ }^{a, b}$ Bharat Bajantri ${ }^{b}$ Muhammad Adrish ${ }^{a, b}$ \\ ${ }^{a}$ Division of Pulmonary and Critical Care Medicine, ${ }^{b}$ Department of Medicine, Bronx-Lebanon Hospital Center, \\ Bronx, N.Y., USA
}

\section{Key Words \\ Transbronchial biopsy · Endobronchial biopsy - \\ Endobronchial ultrasound-guided transbronchial needle aspiration · Echocardiogram · Systolic pulmonary artery pressure}

\begin{abstract}
Background: Bronchoscopy with transbronchial and endobronchial biopsy and transbronchial needle aspiration is an important diagnostic tool in the pulmonologist's armamentarium. Safety in patients with pulmonary hypertension is controversial and many bronchoscopists consider this as a contraindication for the procedure. Objectives: To evaluate safety of bronchoscopy in patients with echocardiographic pulmonary hypertension and to compare with patients without it. Methods: Retrospective analysis of patients who underwent bronchoscopic transbronchial biopsy, endobronchial biopsy and/or endobronchial ultrasound-guided transbronchial needle aspiration. Patients were divided into two groups based on echocardiographic results: control group with systolic pulmonary artery pressure $<36$ and a group with elevated systolic pulmonary artery pressure (eSPAP) $\geq 36$. Results: One-hundred and ninety patients met the study criteria. Patients in the control group were younger
\end{abstract}

with a lower incidence of chronic kidney disease. There was no difference in prevalence of congestive heart failure, obstructive airway disease, malignancy, liver disease, coagulopathy, use of antiplatelet agent or anticoagulant drugs. Incidence of minor bleeding due to bronchoscopic biopsies was $4.8 \%$ in both groups $(p=1.00)$. Incidence of major bleeding was similar in the groups (one patient in each group). In the control group, one patient had pneumothorax and another required prolonged mechanical ventilation $(>4 \mathrm{~h})$. In the eSPAP group, two patients required prolonged mechanical ventilation. There was no procedure-related mortality or sedation complications in the cohort. Conclusion: Our study provides additional support that in patients with echocardiographic evidence of pulmonary hypertension, transbronchial and endobronchial biopsies and endobronchial ultrasound-guided transbronchial needle aspiration are safe procedures.

(C) 2016 The Author(s)

Published by S. Karger AG, Basel

\section{Introduction}

Fiberoptic flexible bronchoscopy (FFB) is an indispensable tool in the evaluation, diagnosis and management of malignant as well as benign pulmonary condi-

\section{KARGER}

E-Mail karger@karger.com www.karger.com/res

\section{C) 2016 The Author(s) \\ Published by S. Karger AG, Basel 0025-7931/16/0923-0182\$39.50/0}

This article is licensed under the Creative Commons AttributionNonCommercial-NoDerivatives 4.0 International License (CC BYNC-ND) (http://www.karger.com/Services/OpenAccessLicense) Usage and distribution for commercial purposes as well as any distribution of modified material requires written permission.
Gilda Diaz-Fuentes, MD, FCCP

Division of Pulmonary and Critical Care Medicine Department of Medicine, Bronx-Lebanon Hospital Center 1650 Grand Concourse, Bronx, NY 10457 (USA)

E-Mail gfuentes@bronxleb.org 
tions. Despite its widespread use, FFB-related complications exist. Minor complications include mild laryngospasm or bronchospasm, hypoxia, epistaxis and injury due to the trauma of nasal passage, minor bleeding, and methemoglobinemia. Serious complications include major bleeding, pneumothorax, cardiac arrhythmias, acute respiratory failure and death. Rate of complications varies from 0.5 to $7 \%$. In patients undergoing transbronchial biopsy (TBBx), major complications have been reported in up to $6.8-10 \%$ [1]. In some studies, TBBxs were avoided in 'high-risk' patients including those with pulmonary hypertension (PH), uremia and thrombocytopenia [1, 2]. Endobronchial ultrasound-guided transbronchial needle aspiration (EBUS-TBNA) is used in conjunction with TBBx to further enhance the diagnostic yield of the procedure [3]. EBUS-TBNA carries a lower risk for serious complications when compared to TBBx, with up to $1.2 \%$ of patients having serious complications [4]. Endobronchial biopsy $(\mathrm{EBBx})$ is often performed for central airway lesions, and biopsy-related hemorrhage can be seen in around of $1 \%$ of the cases [5].

$\mathrm{PH}$ is often considered by pulmonologists as an absolute or relative contraindication for FFB due to the higher risk for bleeding, despite contradictory data in the literature [1]. In addition, there is an increased morbidity and mortality with anesthesia in patients with $\mathrm{PH}$. One study, with a large proportion of patients undergoing minor surgical procedures and regional anesthesia, showed perioperative complications in $29 \%$ of patients with nonsevere $\mathrm{PH}$ [6]. A retrospective study of 90 patients suggested that FFB can be safely performed in patients with mild to moderate $\mathrm{PH}$. However, only 24 patients with $\mathrm{PH}$ underwent TBBx and 7 patients had TBNA in the study, potentially affecting the study power. Associated comorbid conditions that could contribute to procedure-related morbidity were also not considered [7].

Echocardiogram is a reasonable noninvasive method for screening patients for $\mathrm{PH}$. There is conflicting data regarding the reliability of echocardiographic assessment of systolic pulmonary artery pressure (SPAP) to accurately predict severity of PH [8]; Greiner et al. [9] showed that Doppler echocardiography had good diagnostic sensitivity $(87 \%)$, specificity $(79 \%)$ and accuracy $(85 \%)$ for a sPAP cutoff value of $36 \mathrm{~mm} \mathrm{Hg}$. Another study showed an association of sPAP with prognosis in patients with $\mathrm{PH}$ [10].

Delays in FFB may delay diagnosis and treatment of the disease and could affect severity and final prognosis of patients [11]. If patients are deemed high risk for a FFB, there will be reluctance to perform more invasive proce- dures and patients may also refuse a procedure due to anticipated risks.

The aim of our study was to evaluate bronchoscopyrelated complications in patients with echocardiographic evidence of $\mathrm{PH}$. We specifically evaluated patients who underwent bronchoscopic TBBx, EBBx or EBUS-TBNA.

\section{Material and Methods}

\section{Study Design and Setting}

This was a retrospective review of all adult patients who underwent FFB with TBBx, EBBx and EBUS-TBNA between January 2012 and July 2015 at our institution. All procedures were performed by pulmonologists and pulmonary fellows in the endoscopy suite or in the operating room. Sedation and anesthesia were provided by the anesthesiologist in all cases. The study was approved by the hospital institutional review board, and the need for informed consent was waived.

\section{Methods}

We included all adult patients who underwent FFB with TBBx, EBBx and/or EBUS-TBNA who had echocardiogram available. Exclusion criteria: (a) patients who underwent FFB without TBBx, EBBx or EBUS-TBNA, (b) patients with no available echocardiogram or unable to estimate SPAP.

Baseline characteristics and presence of comorbid conditions like congestive heart failure, chronic kidney disease, obstructive airway disease, coagulopathy, malignancy or liver disease were obtained. Information regarding use of antiplatelet or anticoagulant medications and laboratory parameters were collected. Procedural data included use of general anesthetics or conscious sedation, type of procedure and type of complications. Prolonged mechanical ventilation was defined as need for mechanical ventilation for more than $4 \mathrm{~h}$ following the procedure. At our institution, all EBUS-TBNA are performed by one pulmonologist, in the operating room and under general anesthesia.

\section{Definition of Bleeding}

There is no consensus regarding exact definition of minor and major bleeding associated with bronchoscopic biopsy and it is often difficult to precisely calculate blood losses during the procedure. For our study, minor bleeding was defined as bleeding which stopped spontaneously or was controlled with instillation of local epinephrine without further intervention or blood transfusion. Major bleeding was defined when additional interventions were required like balloon tamponade, embolization of blood vessel, surgical intervention or blood transfusion.

\section{Definition of Echocardiographic $\mathrm{PH}$}

Consensus regarding echocardiographic cutoff value of sPAP to accurately predict $\mathrm{PH}$ is not available. A recent report showed a good diagnostic sensitivity (87\%), specificity (79\%) and accuracy (85\%) of Doppler echocardiography for a sPAP cutoff value of 36 $\mathrm{mm} \mathrm{Hg}$ [9]. We classified our patients into two groups: those with sPAP of $<36$ (control group) and patients with $s$ PAP $\geq 36$ (elevated sPAP group or eSPAP group). 
Table 1. Characteristic of patients and pertinent laboratory findings

\begin{tabular}{|c|c|c|c|c|c|}
\hline & $\frac{\text { Control group }(\mathrm{n}=83)}{\text { sPAP } 18-35}$ & \multicolumn{3}{|c|}{ eSPAP group $(n=107)$} & $\mathrm{p}$ \\
\hline Age, years & $54.0 \pm 13.4$ & $57.2 \pm 14.6$ & $59 \pm 11$ & $57.8 \pm 15$ & 0.03 \\
\hline Gender, male & $35(42 \%)$ & 15 & 17 & 20 & 0.88 \\
\hline Body mass index & $26.9 \pm 6.2$ & $24.8 \pm 4.9$ & $27.1 \pm 8.5$ & $24.3 \pm 6$ & 0.14 \\
\hline Chronic kidney disease & $6(7 \%)$ & 6 & 10 & 8 & 0.02 \\
\hline Obstructive airway disease & $33(40 \%)$ & 12 & 22 & 24 & 0.77 \\
\hline Coagulopathy & $3(3 \%)$ & 2 & 4 & 0 & 0.73 \\
\hline Malignancy & $22(27 \%)$ & 5 & 13 & 12 & 0.87 \\
\hline Chronic liver disease & $15(18 \%)$ & 8 & 10 & 7 & 1.00 \\
\hline \multicolumn{6}{|l|}{ Medications } \\
\hline Hemoglobin, mg/dl & $11.2 \pm 2.2$ & $10.4 \pm 1.8$ & $10.5 \pm 2.5$ & $10.93 \pm 2.6$ & 0.07 \\
\hline International normalized ratio & $1.1 \pm 0.3$ & $1.14 \pm 0.19$ & $1.11 \pm 0.16$ & $1.14 \pm 0.26$ & 1.00 \\
\hline Partial thromboplastin time & $31.8 \pm 11.0$ & $31.7 \pm 5.7$ & $29.6 \pm 6$ & $33.6 \pm 6.4$ & 0.87 \\
\hline Thombocytopenia $\left(<150 \times 10^{9} / 1\right)$ & $9(11 \%)$ & 7 & 10 & 8 & 0.052 \\
\hline
\end{tabular}

\section{Subgroup Analysis}

Due to the retrospective analysis, we were not able to assess the adequacy of FFB biopsies. To minimize this bias, we evaluated the total number of biopsies performed in each patient and compared the two groups. In addition, TBBx required presence of alveolus/ lung tissue in pathology specimens.

\section{Statistical Analysis}

Results are expressed as counts (percentage) for discrete variables and as mean \pm SD for continuous variables. For demographic data and clinical characteristics of patients, nominal variables are expressed using $\chi^{2}$ test or Fisher's exact test for categorical variables and Student's t test or Mann-Whitney U test for continuous variables. Statistical significance was defined as $\mathrm{p}<0.05$. Data analysis was conducted using SPSS v15.0.

\section{Results}

One-hundred and ninety patients met the inclusion criteria, 83 in the control and 107 in the eSPAP group. Patients in the control group were younger $(54.0 \pm 13.4$ vs. $58.3 \pm 13.5$ years; $\mathrm{p}=0.03)$. Patients with eSPAP had higher incidence of chronic kidney disease (23 vs. 7\%; $\mathrm{p}=0.02$ ) compared with control group. We found no difference in gender, body mass index, incidence of comorbid conditions, use of antiplatelet or anticoagulant medications or baseline coagulation profile. Median time be- tween echocardiogram and FFB was similar (10 days in control group vs. 9 days in eSPAP group; $p=0.77)$. Evaluation of patient characteristics at different cutoffs of sPAP revealed no differences in the groups (table 1 ).

Review of possible etiologies for $\mathrm{PH}$ in our patients revealed the following conditions: chronic obstructive airway disease (COPD) in 55\%, interstitial lung diseases (ILD) in 34\%, human immunodeficiency syndrome in $27 \%$, portal hypertension due to liver cirrhosis in $18 \%$, chronic left heart failure in $14 \%$, collagen vascular disease in $11 \%$ and obstructive sleep apnea, sarcoidosis, endstage renal disease in less than $10 \%$. Many patients had more than two conditions associated with $\mathrm{PH}$.

\section{Outcome Analysis}

Sixty-nine of $83(83 \%)$ patients in the control group and 91 of 107 (85\%) in eSPAP group underwent TBBx (84.2\% of the cohort). EBBx was performed in 49 patients (25.7\% of the cohort) and EBUS-TBNA in 35 patients (18.4\% of the cohort). Four patients in the control group had minor bleeding compared to 5 patients in the eSPAP group $(p=1.00)$. There was no difference in incidence of major bleeding ( 1 patient in each group; $\mathrm{p}=1.00$ ). One patient in the study had pneumothorax. We found similar incidence of prolonged mechanical ventilation (1 patient in control group vs. 2 in the eSPAP group; $\mathrm{p}=1.00)$. None 
Table 2. Comparison of type of sedation and complications during bronchoscopy

\begin{tabular}{lll}
\hline Variable & $\begin{array}{l}\text { Control } \\
\text { group } \\
(\mathrm{n}=83)\end{array}$ & $\begin{array}{l}\text { group } \\
(\mathrm{n}=107)\end{array}$ \\
\hline
\end{tabular}

$\begin{array}{llll}\text { Type of anesthesia } & & & \\ \text { General } & 41(49 \%) & 46(43 \%) & 0.46 \\ \text { Conscious sedation } & 42(51 \%) & 61(57 \%) & \end{array}$

\begin{tabular}{llll}
\hline Complications & & & \\
Minor bleeding requiring intervention & 4 & 5 & 1.00 \\
$\begin{array}{l}\text { Major bleeding } \\
\text { Pneumothorax }\end{array}$ & 1 & 1 & 1.00 \\
$\begin{array}{l}\text { Prolonged mechanical ventilation } \\
\quad(>4 \mathrm{~h})\end{array}$ & 1 & 0 & 0.44 \\
\hline
\end{tabular}

of patients in the study required mechanical ventilation beyond $24 \mathrm{~h}$. There were no arrhythmic events or procedure-related mortality in our cohort (table 2).

\section{Subgroup Analysis}

Subgroup analysis evaluating number of biopsies per patient per procedure found no difference in the median number of TBBx [ 6 biopsies per procedure in the control (range 2-11) vs. 6 biopsies per procedure in the eSPAP group (range 2-9); $\mathrm{p}=0.53$ ], EBBx [4 biopsies per procedure in the control (range 2-8) vs. 4 biopsies per procedure in the eSPAP group (range 2-14); $\mathrm{p}=0.21$ ] and EBUS-TBNA [3 passes per procedure in the control (range 3-7) vs. 6 passes per procedure in the eSPAP group (range 3-10); $p=0.12$ ] (table 3). Summary of the procedures performed did not reveal any significant difference between the 2 groups (table 4 ).

The main indication for EBUS-TBNA was evaluation for possible malignancy or sarcoidosis in both groups. Despite the nonsignificant difference in lymph node biopsies in EBUS-TBNA, the diagnostic yield was similar, $30 \%$ in the control group and $24 \%$ in the eSPAP group.

\section{Discussion}

We demonstrate that FFB is safe in patients with echocardiographic evidence of PH. Furthermore, we found no increased risk for prolonged mechanical ventilation, cardiac arrhythmias or mortality. Major complications due to FFB are rare and reported mainly with TBBx [4]. Safety of FFB has also been evaluated in patients with other conditions such as COPD, acute myocardial infarction, renal insufficiency, coagulopathy and malignant spaceoccupying brain lesions. In general, those studies suggested that FFB can be safely performed with a low incidence of procedure-related complications [12-14].

The potential increase risk for complications in patients with PH undergoing FFB are due to cardiovascular compromise due to right ventricular dysfunction leading to cardiac arrhythmia, ischemia and hemodynamic compromise. In addition, due to chronic venous $\mathrm{PH}$, dilation of submucosal bronchial veins and their plexuses exist making bleeding potentially more common $[7,12]$. There are few studies looking specifically at complications of FFB in this selective group of patients, and most guidelines in FFB have no specific recommendations for $\mathrm{PH}$. Furthermore, there is no consensus regarding which levels of pulmonary artery pressure are considered safe for TBBx or TBNA.

In a prospective study by Neuman and colleagues [15], they reported an increased incidence of hypoxemia during TBBx in 40 patients with COPD and PH. No increase in bleeding was found and overall the procedure was safe.

Another prospective study in 50 patients with ILD and no clinical or radiographic evidence of $\mathrm{PH}$ who underwent TBBx revealed $\mathrm{PH}$ (defined as $\mathrm{SPAP}>30 \mathrm{~mm} \mathrm{Hg}$ or evidence of right-sided chamber enlargement) in $44 \%$ of the patients. They found no significant difference in bleeding between the $\mathrm{PH}$ and the control group [16].

Diaz-Guzman et al. [7] reported the safety of FFB in 90 patients with mild and moderate $\mathrm{PH}$, but this study was limited by the retrospective nature and few patients undergoing TBBx. In our patients, COPD and ILD were common, and our data support these studies regarding the safety of FFB.

Hemodynamic complications after bronchoscopy are uncommon with an incidence of cardiac arrhythmia of $1 \%$ [17]. In a large review of 107,969 bronchoscopies, the incidence of complication due to local anesthesia was $0.3-0.5 \%$, pneumothorax and pneumomediastinum $1-6 \%$, and mortality rate $0.1-0.2 \%$ [18].

Pulmonary arterial hypertension is characterized by a progressive increase in pulmonary arterial pressure $(\mathrm{PH}$ defined as mean pulmonary arterial pressure $\geq 25 \mathrm{~mm} \mathrm{Hg}$ at rest or $30 \mathrm{~mm} \mathrm{Hg}$ during exercise) in association with variable degrees of pulmonary vascular remodeling, vasoconstriction, and in situ thrombosis. Chronic $\mathrm{PH}$ leads to progressive right ventricle systolic pressure overload resulting in gradual right ventricular dysfunction. The increase in pulmonary vascular resistance gradually worsens right ventricular failure. Decreased venous return compromises right ventricular preload and pulmonary blood flow. Patients with $\mathrm{PH}$ undergoing sedation and 
Table 3. Comparison of number of bronchoscopic biopsies or passes

\begin{tabular}{lccc}
\hline Procedure & Control group & eSPAP group & p \\
\hline TBBxs per patient, median (range) & $6(2-11)$ & $6(2-9)$ & 0.53 \\
$\quad$ Number of patients who underwent TBBx & 69 & 91 & $\mathrm{z} \mathrm{score}-0.623$ \\
EBBx per patient, median (range) & $4(2-8)$ & $4(2-14)$ & 0.21 \\
$\quad$ Number of patients who underwent EBBx & 25 & 24 & $\mathrm{Z} s c 0 r e-1.25$ \\
EBUS-TBNA passes per patient, median (range) & $3(3-7)$ & $6(3-10)$ & 0.12 \\
$\quad$ Number of patients who underwent EBUS-TBNA & 10 & 25 & $\mathrm{z}$ score -1.563535 \\
\hline
\end{tabular}

anesthesia represent a unique perioperative challenge due to changes in preload and afterload induced by fluid shifts, changes in autonomic nervous system and medications administered during the procedure $[19,20]$. Hypercarbia, hypoxia, acidosis and noxious stimuli from pain and airway stimulation can also increase pulmonary arterial pressure $[19,21]$. Increased perioperative morbidity and mortality of adult patients with $\mathrm{PH}$ has been well described in patients undergoing cardiac and noncardiac surgery [22]. In our study, close to $50 \%$ of patients with $\mathrm{PH}$ underwent FFB under general anesthesia and positive pressure ventilation without complications.

Due to unique challenges attributed to $\mathrm{PH}$ patients undergoing bronchoscopic biopsy, this has been an area of concern [23, 24]. Schulman et al. [25] reported an incidence of $15 \%$ for moderate hemorrhage in patients with mean pulmonary arterial pressure higher than $16 \mathrm{~mm}$ Hg.

We additionally accounted for other predictors of procedure-related morbidity and mortality such as prevalence of underlying congestive heart failure, liver disease, renal failure, or use of antiplatelet/anticoagulant agents. We also compared for differences in the number of biopsies performed in each patient.

There are several limitations in our study. First, there might be a selection bias because this is a retrospective study in a single center. Second, we were not able to correlate echocardiographic findings of $\mathrm{PH}$ with right-side cardiac catheterization. Third, echocardiograms were not performed on the same day of FFB; however, 54\% patients in the control and $60 \%$ in the eSPAP group had echocardiogram done within 2 weeks of bronchoscopy. Furthermore, the total number of major complications was very low; using a stricter cutoff for the interval between echocardiogram and FFB would not have changed the outcomes. Fourth, in view of the retrospective nature of the study, we are not able to comment on the technique and adequacy of sampling of each pulmonary biopsy. We compensated by reviewing number of biopsies for each
Table 4. Comparison of bronchoscopic procedures

\begin{tabular}{lcll}
\hline Procedures & $\begin{array}{l}\text { Control } \\
\text { group } \\
\text { SPAP }<36 \\
(\mathrm{n}=83)\end{array}$ & $\begin{array}{l}\text { eSPAP } \\
\text { group } \\
\text { SPAP } \geq 36 \\
(\mathrm{n}=107)\end{array}$ & $\mathrm{p}$ \\
\hline EBUS-TBNA only & 3 & 4 & 1.00 \\
EBBx only & 11 & 8 & 0.22 \\
TBBx only & 50 & 66 & 0.88 \\
EBUS-TBNA + TBBx + EBBx & 2 & 6 & 0.46 \\
EBUS-TBNA + TBBx & 5 & 12 & 0.30 \\
TBBx + EBBx & 12 & 7 & 0.08 \\
EBUS-TBNA + EBBx & 0 & 3 & 0.25 \\
\hline
\end{tabular}

patient and review of pathology report. Fifth, patients in our control group were younger that patients with $\mathrm{PH}$.

Our study is the largest case control study evaluating the outcomes of bronchoscopic biopsies in patients with $\mathrm{PH}$ while accounting for important comorbid conditions and medications that could potentially contribute to procedure-related morbidity and mortality.

\section{Conclusions}

Our study demonstrates that bronchoscopic TBBx, EBBx and EBUS-TBNA with either conscious sedation or general anesthesia can be safely performed in patients with echocardiographic diagnosis of $\mathrm{PH}$. Careful perioperative planning of the procedure and sedation can minimize any potential complication.

\section{Financial Disclosure and Conflicts of Interest}

None of the authors has a financial relationship with a commercial entity that has an interest in the subject of the manuscript. No financial support was used for the study. The authors declare that they have no competing interests. 


\section{References}

$>1$ Pue CA, Pacht ER: Complications of fiberoptic bronchoscopy at a university hospital. Chest 1995; 107:430-432.

-2 Bechara R, Beamis J, Simoff M, Mathur P, Yung R, Feller-Kopman D, Ernst A: Practice and complications of flexible bronchoscopy with biopsy procedures. J Bronchol 2005; 12: 139-142.

3 Agarwal R, Aggarwal AN, Gupta D: Efficacy and safety of conventional transbronchial needle aspiration in sarcoidosis: a systematic review and meta-analysis. Respir Care 2013; 58:683-693.

$\checkmark 4$ Eapen GA, Shah AM, Lei X, Jimenez CA, Morice RC, Yarmus L, Filner J, Ray C, Michaud G, Greenhill SR: Complications, consequences, and practice patterns of endobronchial ultrasound-guided transbronchial needle aspiration: results of the AQuIRE registry. Chest 2013;143:1044-1053.

$\checkmark 5$ Asano F, Aoe M, Ohsaki Y, Okada Y, Sasada S, Sato S, Suzuki E, Senba H, Fujino S, Ohmori K: Deaths and complications associated with respiratory endoscopy: a survey by the Japan Society for Respiratory Endoscopy in 2010. Respirology 2012;17:478-485.

$\checkmark 6$ Price LC, Montani D, Jaïs X, Dick JR, Simonneau G, Sitbon O, Mercier FJ, Humbert M: Noncardiothoracic nonobstetric surgery in mild-to-moderate pulmonary hypertension. Eur Respir J 2010;35:1294-1302.

7 Diaz-Guzman E, Vadi S, Minai OA, Gildea TR, Mehta AC: Safety of diagnostic bronchoscopy in patients with pulmonary hypertension. Respiration 2009;77:292-297.

$>8$ Fisher MR, Forfia PR, Chamera E, HoustenHarris T, Champion HC, Girgis RE, Corretti MC, Hassoun PM: Accuracy of Doppler echocardiography in the hemodynamic assessment of pulmonary hypertension. Am J Respir Crit Care Med 2009;179:615-621.
-9 Greiner S, Jud A, Aurich M, Hess A, Hilbel T, Hardt S, Katus HA, Mereles D: Reliability of noninvasive assessment of systolic pulmonary artery pressure by Doppler echocardiography compared to right heart catheterization: analysis in a large patient population. J Am Heart Assoc 2014;3:e001103.

10 Corciova FC, Arsenescu-Georgescu C: Prognostic factors in pulmonary hypertension Maedica (Buchar) 2012;7:30-37.

11 Sawicki M, Szczyrek M, Krawczyk P, Rybojad P, Jabłonka A, Milanowski J: Reasons for delay in diagnosis and treatment of lung cancer among patients in Lublin Voivodeship who were consulted in Thoracic Surgery Department. Ann Agric Environ Med 2013;20:7276.

12 Dweik RA, Mehta AC, Meeker DP, Arroliga AC: Analysis of the safety of bronchoscopy after recent acute myocardial infarction. Chest 1996;110:825-828.

13 Grosu HB, Morice RC, Sarkiss M, Bashoura L, Eapen GA, Jimenez CA, Faiz S, Lazarus DR, Casal RF, Ost DE: Safety of flexible bronchoscopy, rigid bronchoscopy, and endobronchial ultrasound-guided transbronchial needle aspiration in patients with malignant space-occupying brain lesions. Chest 2015;147:16211628 .

14 Hattotuwa K, Gamble EA, O’Shaughnessy T, Jeffery PK, Barnes NC: Safety of bronchoscopy, biopsy, and BAL in research patients with COPD. Chest 2002;122;1909-1912.

15 Neuman Y, Koslow M, Matveychuk A, BarSef A, Guber A, Shitrit D: Increased hypoxemia in patients with COPD and pulmonary hypertension undergoing bronchoscopy with biopsy. Int J Chron Obstruct Pulmon Dis 2015; 10:2627-2632.
16 Morris MJ, Peacock MD, Mego DM, Johnson JE, Anders GT: The risk for hemorrhage from bronchoscopic lung biopsy due to pulmonary hypertension in interstitial lung disease. J Bronchology 1998;5:117-121.

17 Jin F, Mu D, Chu D, Fu E, Xie Y, Liu T: Severe complications of bronchoscopy. Respiration 2008;76:429-433.

18 Geraci G, Pisello F, Sciumè C, Li Volsi F, Romeo M, Modica G: Complication of flexible fiberoptic bronchoscopy. Literature review. Ann Ital Chir 2007;78:183-192.

19 Minai OA, Yared JP, Kaw R, Subramaniam K, Hill NS: Perioperative risk and management in patients with pulmonary hypertension. Chest 2013;144:329-340.

20 Piazza G, Goldhaber SZ: The acutely decompensated right ventricle: pathways for diagnosis and management. Chest 2005;128:18361852.

-21 Blaise G, Langleben D, Hubert B: Pulmonary arterial hypertension pathophysiology and anesthetic approach. Anesthesiology 2003;99: 1415-1432.

22 Ramakrishna G, Sprung J, Ravi BS, Chandrasekaran K, McGoon MD: Impact of pulmonary hypertension on the outcomes of noncardiac surgery: predictors of perioperative morbidity and mortality. J Am Coll Cardiol 2005;45:1691-1699.

23 Prakash UB, Offord KP, Stubbs SE: Bronchoscopy in North America: the ACCP survey. Chest 1991;100:1668-1675.

24 Zavala DC: Pulmonary hemorrhage in fiberoptic transbronchial biopsy. Chest 1976;70: 584-588.

25 Schulman LL, Smith CR, Drusin R, Rose EA, Enson Y, Reemtsma K: Utility of airway endoscopy in the diagnosis of respiratory complications of cardiac transplantation. Chest 1988;93:960-967. 